\title{
Bioprocess Design: Fermentation Strategies for Improving the Production of Alginate and Poly- $\beta$-Hydroxyalkanoates (PHAs) by Azotobacter vinelandii
}

\author{
Carlos Peña, Tania Castillo, \\ Cinthia Núñez and Daniel Segura \\ Instituto de Biotecnología, \\ Universidad Nacional Autónoma de México (UNAM) \\ México
}

\section{Introduction}

Industrial interest in microbial polymers has been stimulated by their unique properties and the opportunity to develop new materials, which can be used for specific applications in medical and pharmaceutical industries. Azotobacter vinelandii produces two polymers of biotechnological importance; alginate, an extracellular polysaccharide, and poly- $\beta$ hydroxybutyrate (PHB), an intracellular polyester of the polyhydroxyalkanoates (PHAs) family (Galindo et al., 2007). Alginates are linear polysaccharides composed of variable amounts of (1-4)- $\beta$-D-mannuronic acid and its epimer, a-L-guluronic acid. Alginates present a wide range of applications, acting as stabilizing, thickening, gel or film-forming agents, in various industrial fields. Currently, new applications are being discovered for these polymers, such as their use as a source of soluble fiber, or in medical products. One example is found in the use of alginate gel beads as entrapment devices for transplantation of e. $\mathrm{g}$. insulin producing cells and tissue engineering (Hernández et al., 2010).

The intracellular polyester PHB and other PHAs have been drawing attention because they are biodegradable and biocompatible thermoplastics, which can be processed to create a wide variety of consumer products, including plastics, films, and fibers (Aldor \& Keasling, 2003). Recently, and based on their properties of biocompatibility and biodegradability, new attractive applications for PHAs have been proposed in the medical field, where the chemical composition and product purity are critical (Williams \& Martin, 2005).

The subjects covered in this chapter include research concerning the production of alginate and $\mathrm{PHB}$ by $A$. vinelandii, particularly the molecular regulation of the production of these polymers, the influence of fermentation parameters on the production and composition of alginate and $\mathrm{PHB}$, some reports about the scaling-up of the process and downstream processing, and finally, novel fermentation strategies that could be applied for the production of alginate and PHAs by A. vinelandii. 


\section{Structure and physical properties of alginate and PHAs}

Alginates are polysaccharides constituted by variable amounts of $\beta$-D-mannuronic acid and its C5-epimer a-L-guluronic acid linked by 1-4 glycosidic bonds (Figure 1). The monomers are distributed in blocks of continuous mannuronate residues $(\mathrm{M})$, guluronate residues $(\mathrm{G})$ or alternating residues (MG) (Smidsrod \& Draget,1996). Azotobacter alginates are true block co-polymers, composed of homopolymeric regions of $M$ and $G$ residues, separated by regions of alternating structure (Clementi, 1997). Unlike alginates produced by algae, bacterial alginates are acetylated to a variable extent at positions O-2 and/or O-3 of the mannuronate residues (Skjak-Braek et al., 1986). The variability in molecular mass, monomer block structure and acetylation influence the physicochemical and rheological characteristics of the polymer.

The capability of alginate to confer viscosity in solution is dependent on its molecular mass (MM). The MM of algal alginates has been found to range from 48 to $186 \mathrm{kDa}$ (Donnan \& Rose, 1950). In contrast, some alginates isolated from $A$. vinelandii present $M M$ in the range of 80 to $4,000 \mathrm{kDa}$ (Galindo et al., 2007).

The gelling properties of alginate are based on the affinity of the molecule towards certain ions, especially $\mathrm{Ca}^{++}$, and the ability to bind these ions selectively and cooperatively. Selective ion binding is related to the content of $\mathrm{G}$ residues, in particular the length of the Gblocks. Alginates rich in $\mathrm{G}$ residues show an increased ionic binding, resulting in enhanced mechanical rigidity (Grant et al., 1973). Alginates with a low M/G ratio form strong and brittle gels, while alginates with a high $\mathrm{M} / \mathrm{G}$ ratio form weaker and softer, but more elastic gels (Skjak-Braek et al., 1986).

Bacterial alginates which are $\mathrm{O}$-acetylated, have a polyelectrolyte behaviour different from that of the non-acetylated algal alginates. This is because acetyl groups strongly perturb stereoregular sequences and produce significant conformational effects. In addition, the presence of acetyl groups diminishes the binding capacity and the selectivity coefficient for cations, affecting the gelling properties of alginate. The presence of $O$-acetyl groups in bacterial alginates might represent an advantage for certain applications, as it has been demonstrated that they improve the viscosity and enhance the swelling ability of the polymer (Clementi, 1997; Peña et al., 2006).

On the other hand, polyhydroxyalkanoates (PHAs) are aliphatic polyesters generally composed of $\beta$-hydroxy fatty acid monomers in which the carboxyl group of one monomer forms an ester bond with the hydroxyl group of the neighboring monomer (Madison \& Huisman, 1999; Figure 1). The MM of PHAs is dependent on the bacterial species used and culture conditions but is generally on the order of 50 to 1,000 kDa (Madison \& Huisman, 1999). At present, more than 150 different hydroxyalkanoate constituents have been reported in PHAs, as homopolyesters or as copolyesters (Steinbuchel \& Lutke-Eversloh, 2003). These highly diverse polymers can be classified according to the size of the comprising monomers. PHAs containing monomers with $\mathrm{C} 4-\mathrm{C} 5$ atoms are categorized as short-chain-length PHAs (scl-PHAs). In contrast, medium-chain-length PHAs (mcl-PHAs) are composed of C6-C14 $\beta$-hydroxy fatty acids (Lee, 1996). Most bacteria synthesize either scl-PHAs or mcl-PHAs (Madison \& Huisman, 1999). scl-PHAs have properties close to conventional plastics, while the mcl-PHAs are regarded as elastomers and rubbers (Suriyamongkol et al., 2007).

Polyhydroxybutyrate (PHB) is the more abundant PHA and has been studied extensively. This polymer has some mechanical properties similar to conventional plastics like 
polypropylene or polyethylene, although it is highly crystalline and stiff, leading to brittleness and low elongation to break (Khanna \& Srivastava, 2005). Initial biotechnological developments were aimed at making PHAs easier to process. Because the monomeric composition of a PHA is crucial for its mechanical properties, the incorporation in the PHB polymer of secondary monomer units(s) such as $\beta$-hydroxyvalerate (3HV) improves the characteristics of the material obtained. For example, a random copolymer of $3 \mathrm{HB}$ and $3 \mathrm{HV}$ is more ductile, easier to mold, and tougher than PHB homopolymer (Taguchi \& Doi, 2004), and it can be used to prepare films with excellent water and gas barrier properties reminiscent of polypropylene, and can be processed at a lower temperature while retaining most of the other mechanical properties of PHB.

b)
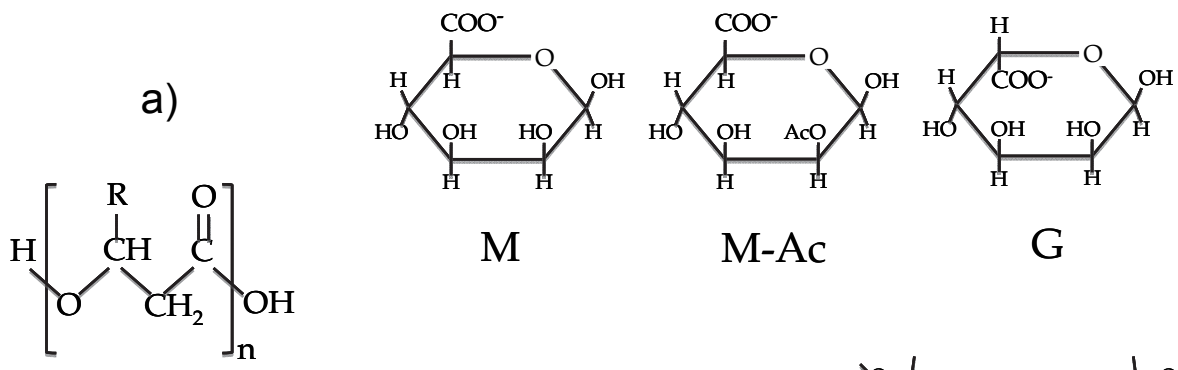

M-Ac

G

PHAs

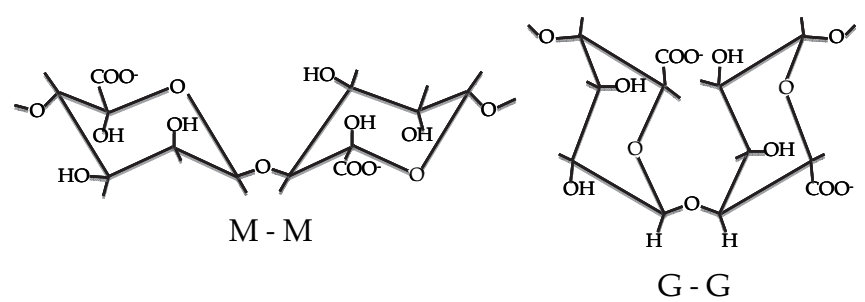

Fig. 1. Chemical structure of PHAs (a) and Alginate (b). M, mannuronic acid; G, guluronic acid; Ac, acetyl. R, alkyl group.

\section{Novel applications of alginate and PHAs}

\subsection{Novel applications of alginates}

Novel alginates applications have been focused on pharmaceutical and biomedical fields, because they are non-toxic, biocompatible, non-immunogenic, hydrophilic and biodegradable material (Augst et al., 2006; Hernández et al., 2010). Alginate hydrogels can be used as bulking materials for in vivo and in vitro cell immobilization, like drug controlled delivery system, for tissue engineering (Augst et al., 2006; Hernández et al., 2010), and alginate conjugates have also been tested as antigens to control cystic fibrosis (Kashef et al., 2006), and other bacterial infections (H. Sun et al., 2007). During the last three decades, microencapsulation using alginate has been investigated to deliver and protect from the host immune system, not only drugs, but also transplanted cells (Hoesli et al., 2011). The materials used for these molecular/cell immobilization require to be biocompatible and bioinert, with certain size and shape. In addition, alginates have been used as scaffold for tissue 
engineering, and chemical modifications that increase alginate biocompatibility or cell adhesion have been developed. The polysaccharide can be modified by coupling proteins and peptides, allowing the control of cell attachment (Augst et al., 2006; Hernández et al., 2010). The biomimetic gel design provides in vivo long-term functionality and higher mechanical stability (Hernández et al., 2010).

Some therapeutic applications of alginate microencapsulation are related with drug delivery. For low-molecular weight drugs, regulating drug-alginate interactions in alginate gels allows the control of drug release. This is especially important for drugs that have severe side effects, like antineoplastic agents. Besides, some proteins with therapeutic activities can be alginate-microencapsulated to improve their efficacy and targeting, because alginate encapsulation facilitate a localized delivery without adverse side effects. Alginate microencapsulation has been proven with basic fibroblast growth factor (bFGF) and vascular endothelial growth factor (VEGF). The release of VEGF is controlled by the dissolution of the ionic binding complex between alginate and VEGF and subsequent diffusion, showing a constant release rate for several weeks (Augst et al., 2006).

Alginate has been successfully used for cell microencapsulation, which is of great importance for Diabetes Mellitus type 1 treatment, where several efforts have been made for regulated insulin supply for treating insulin-dependent patients (Hernández et al., 2010). Moreover, there are several new strategies developed to improve the cell-alginate immobilization process (Hoesli et al., 2011), as well as immune protection and oxygen supply to avoid hypoxia problems during transplants (Ludwig et al., 2010). In the tissue engineering field, alginate has been used for bone regeneration therapy using coimmobilization of human osteoprogenitors and endothelial cells in studies in vivo and in vitro (Hernández et al., 2010). Other important applications of alginate for tissue engineering are related to neurological and cardiologic tissue regeneration (Hernández et al., 2010).

Pseudomonas aeruginosa is the most common pathogen responsible for morbidity and mortality in cystic fibrosis patients. During infection, this bacterium produces alginate, which is an important virulence factor (Kashef et al., 2006). For this reason, alginate has been used for vaccine design, against $P$. aeruginosa. Vaccines based on purified alginate bring poor immunogenicity (Dörig \& Pier, 2008); however, when alginate is conjugated with proteins, the immune response could be enhanced (Dörig \& Pier, 2008; Kashef et al., 2006). Kashef et al., (2006) designed an alginate-tetanus toxoid conjugate non-toxic, non pyrogenic, which was able to protect mice against a lethal dose of mucoid $P$. aeruginosa. It is important to point out that alginate viscosity plays an important role for the $P$. aeruginosa protection during the infection process. Because of this, it has been proposed to induce changes in the rheology of the alginate by addition of alginate olygoelectrolytes conformed by $\mathrm{G}$ blocks only (Draget \& Taylor, 2011). These oligoguluronates reduce the mechanical response of the polymer synthesized by $P$. aeruginosa in patients diagnosed with cystic fibrosis (Draget \& Taylor, 2011).

Alginates have also been studied for development of novel immunotherapy strategies for cancer treatment using dendritic cells which are potent initiators of immune response. Calcium cross-linked alginate gels carrying dendritic cells initiated the immune response and allowed the migration of the immune cells through the alginate gel (Hori et al., 2008, 2009).

\subsection{Novel applications for PHAs}

PHAs have received much attention as candidates to produce biodegradable plastics compatible with the environment, due to their material properties (similar to those of well- 
known plastics such as polypropylene), their production from renewable sources, and their inherent biodegradability in various environments (Taguchi \& Doi, 2004). These biopolyesters are attractive to replace non-biodegradable plastics, especially for those products that usually have single-use applications, such as food packaging.

\begin{tabular}{|c|c|c|c|}
\hline Material & Application & Desirable properties & Reference \\
\hline \multirow[t]{6}{*}{ Alginate } & Drug delivery & $\begin{array}{c}\text { Gel formation/ } \\
\text { Biocompatible/ } \\
\text { Bioinert/ Biodegradable/ } \\
\text { Drug alginate interaction }\end{array}$ & Augst et al., 2006 \\
\hline & $\begin{array}{l}\text { Cell } \\
\text { immobilization }\end{array}$ & $\begin{array}{l}\text { Gel formation/ } \\
\text { Biocompatible/ } \\
\text { Bioinert/ Diffusion }\end{array}$ & $\begin{array}{l}\text { Hernández et al., } 2010 \\
\text { Hoesli et al., } 2011\end{array}$ \\
\hline & Tissue Engineering & $\begin{array}{c}\text { Gel formation/ } \\
\text { Biocompatible/ } \\
\text { Bioinert/Diffusivity }\end{array}$ & Hernández et al., 2010 \\
\hline & $\begin{array}{l}\text { Vaccines against } \\
\text { Pseudomonas } \\
\text { aeruginosa }\end{array}$ & Immunogenicity & Kashef et al., 2006 \\
\hline & Mucus alteration & Low Viscosity & Draget \& Taylor, 2011 \\
\hline & Cancer therapy & $\begin{array}{c}\text { Gel formation/ } \\
\text { Biocompatible/ } \\
\text { Bioinert/ Diffusivity }\end{array}$ & Hori et al., 2008 \\
\hline \multirow[t]{8}{*}{ PHA } & Bioplastics & $\begin{array}{c}\text { Thermoplasticity, physical and } \\
\text { mechanical resistance/ } \\
\text { Biodegradable }\end{array}$ & Chen, 2009 \\
\hline & Tissue Engineering & $\begin{array}{c}\text { Thermoplasticity, physical and } \\
\text { mechanical resistance/ } \\
\text { Biocompatible }\end{array}$ & $\begin{array}{l}\text { Wu et al., } 2009 \\
\text { Grage et al., } 2009\end{array}$ \\
\hline & Drug delivery & Biocompatible/ Biodegradable & Chen, 2009 \\
\hline & $\begin{array}{l}\text { Cell } \\
\text { microencapsulation } \\
\text { and } \\
\text { nanoencapsulation }\end{array}$ & Biocompatible/ Biodegradable & Grage et al., 2009 \\
\hline & Affinity support & Biocompatible & $\begin{array}{l}\text { Lee et al., } 2005 \\
\text { Wang et al., } 2008\end{array}$ \\
\hline & $\begin{array}{l}\text { Affinity } \\
\text { chromatography }\end{array}$ & Biocompatible & \\
\hline & $\begin{array}{l}\text { Biomarkers/ } \\
\text { Biosensors }\end{array}$ & Biocompatible & Grage et al., 2009 \\
\hline & Biofuels & $\begin{array}{c}\text { Biodegradability/ Methyl } \\
\text { esterification capability }\end{array}$ & Zhang et al., 2009 \\
\hline
\end{tabular}

Table 1. Novel applications of Alginate and PHAs. 
Some of the monomers present in PHAs are known to be present in human and animals. For example, the monomeric component of $\mathrm{PHB}$ ( $\beta$-hydroxybutyrate) is a ketone body normally found in human blood (Williams \& Martin, 2005). The biocompatibility, together with the adjustable mechanical properties, and controllable biodegradability of PHAs have raised interesting applications in the medical field. These polymers have been used in artificial organ construction, drug delivery, tissue repair, and nutritional/therapeutic uses (Chen \& Wu, 2005; Freier, 2006; Grage et al., 2009; Valappil et al., 2006; Williams \& Martin, 2005; Wu et al., 2009; Zinn et al., 2001). Because several PHAs are available now in sufficient quantity, some of them have been used in biocompatibility studies in vivo (Valappil et al., 2006). Some of the medical devices tested with different degrees of success include meniscus repair devices, staples, screws, bone plating systems, cardiovascular patches, stents and nerve guides (Wu et al., 2009).

Very interesting applications for PHAs are found in the fabrication of drug delivery devices. Their biocompatibility, combined with their biodegradation, make them good candidates for this purpose (Chen, 2009). The possibility to create PHAs of various monomeric compositions and molecular weights makes possible the fine control of their degradation rate (Wu et al., 2009). Several drugs have been entrapped or microencapsulated in PHA homopolymers or copolymers, such as, anticancer agents, antihypertensives, hormones, vaccines, etc. (Williams \& Martin, 2005).

More recently, new applications have been reported for PHAs, not just as a material but for the PHA granules themselves as micro-nano beads, resulting in applications for protein purification and specific drug delivery (Grage et al., 2009). Affinity protein purification methods make use of an affinity tag fused to the protein of interest. The interaction of the tagged protein with an immobilizing matrix allows the separation of the protein. PHA granules have been used as an inexpensive affinity support, while the phasins, PHA synthase, or PHA depolymerase, proteins naturally associated with the granules, work as the affinity tag for the purification or immobilization of proteins (Lee et al., 2005; Wang et al., 2008). Combining the fusion of the protein of interest with the phasin protein (PhaP), intein mediated self-cleavage, and PHA synthesis in recombinant Escherichia coli, specific proteins can be produced together with their insoluble matrix, and after cell disruption, precipitation and selfcleavage, the purified protein is released (Banki et al., 2005; Mee at al., 2008). A similar method using Cupriavidus necator instead of E. coli has been developed (Barnard et al., 2005).

PHA nanoparticles have also been used in drug delivery, target specific therapy and as biomarkers or biosensors (Grage et al., 2009). Using the same principle of affinity binding of PHA synthase to PHA granules, Brockelbank et al., (2006) demonstrated the display of antigen fragments at the surface of PHA beads, showing their potential to be used in immunoglobulin $\mathrm{G}(\mathrm{IgG})$ purification from human serum. The functional display of antigen or antibodies fragments at the bead surface can be used for diagnostic or therapeutic applications (Grage et al., 2009). Fusion of PHA synthase with streptavidin has shown that these PHA beads can also be used for ELISA, DNA purification, enzyme immobilization and flow cytometry (Peters \& Rhem, 2008). Engineered proteins for inorganics, like gold or silica, or IgG, have also been fused to the PHA synthase, and displayed at the surface of PHA granules, so these biobeads can be used for medical bioimaging procedures as inorganic contrast agents (Grage et al., 2009; Jahns et al., 2008).

With respect to targeted drug delivery, Yao et al., (2008) demonstrated that phasins can be fused to ligands recognized by tissue specific receptors, and that the ligand-PhaP-nanobeads are taken up by the correct tissue in vivo, delivering drugs loaded in the PHA beads. 
Other applications for PHAs include their use as fine chemicals. A high diversity of carboxylic acids, all in the (R)- configuration, can be obtained by depolymerization or by chemical degradation of PHAs, and these can be bulk chemicals for various applications (Chen, 2009). Some of them have been used as starting material for the synthesis of antibiotics, vitamins, aromatics and pheromones (Ruth et al., 2007).

A new field of application for PHAs has been devised in the energy industry. These polymers can be used as biofuels (Chen, 2009). The conversion of PHB or mcl-PHAs to their methyl ester derivatives by acid catalyzed hydrolysis, allowed their use as fuels in blends with ethanol, gasoline, and diesel, with reasonable combustion heats (Zhang et al., 2009).

\section{Azotobacter vinelandii}

A. vinelandii is a gamma Proteobacteria having a strictly respiratory type of metabolism with oxygen as the terminal electron acceptor. Nitrogen is fixed at either microaerobic or fully aerobic conditions. Its growth is heterotrophic where sugars, alcohols and salts of organic acids are used as carbon source (Kennedy et al., 2005). Sugars are metabolized trough the Entner-Doudoroff pathway (Conway, 1992). The genus Azotobacter is distinguished by the ability to form metabolically dormant cyst in stationary phase or upon induction of vegetative cells with $0.2 \%$ of $n$-butanol. The cysts are significantly more resistant than vegetative cells to desiccation (Socolofsky \& Wyss, 1962). Alginate is a component of the envelope that protects the cyst, and is essential for the resistance to desiccation (Campos et al., 1996). Upon induction of encystment intracellular accumulation of poly- $\beta$ hydroxybutyrate (PHB) occurs at an exponential rate; however recent data demonstrated that PHB was not essential for the formation of mature cysts (Segura et al., 2003a).

The majority of nitrogen fixing bacteria are capable of reducing $\mathrm{N}_{2}$ only in anaerobic or microaerobic conditions. In contrast, $A$. vinelandii is an obligate aerobe capable of fixing $\mathrm{N}_{2}$ even at high concentration of $\mathrm{O}_{2}$. This is possible because this bacterium can adjust oxygen consumption rates to help maintain low levels of cytoplasmic oxygen, which is otherwise detrimental not only for nitrogenase, but also to other oxygen-sensitive enzymes, a process that has been called respiratory protection (Poole \& Hill, 1997). In addition to the respiratory protection of the nitrogenase, another way to keep the cytoplasm anaerobic is to prevent the $\mathrm{O}_{2}$ transfer into the cell. The polysaccharide alginate is believed to form a coating around the cell, acting as a physical $\mathrm{O}_{2}$ barrier (Sabra et al., 2000). This barrier has also been reported to protect the cell from heavy metals toxicity, as an ion-exchange system with high affinity to $\mathrm{Ca}^{++}$, or to provide a negatively charge coating which creates a barrier against attack and adverse environmental conditions (Clementi, 1997).

\section{Genetics and biosynthesis of alginates and PHAs in A. vinelandii}

\subsection{Biosynthesis of alginates by $A$. vinelandii}

The pathway for alginate synthesis has been well established and it is conserved among brown algae, Pseudomonas and Azotobacter spp. (Lynn \& Hassid, 1966; Pindar \& Bucke, 1975). Fructose 6-P, the precursor of this metabolic pathway, is converted by four enzymatic reactions to GDP-mannuronic acid (for a detailed review see Galindo et al., 2007; Remminghorst \& Rehm 2006). Polymerization of GDP-mannuronic acid is conducted by an inner membrane mannuronate polymerase (Alg8) and its activity is regulated by another inner membrane protein (Alg44), essential for alginate biosynthesis (Galindo et al., 2007). 
The resultant poly-mannuronic acid is then modified by a periplasmic $O$-acetylase complex (AlgI, $\mathrm{Alg} \mathrm{V}, \mathrm{AlgF}$ ) and some of the non-acetylated mannuronate residues are epimerized to guluronate by a periplasmic mannuronate epimerase (AlgG). The polymer is then exported through the outer membrane via the pore-forming protein AlgJ where the activity of several extracellular C-5 epimerases (AlgE1-7), present only in A. vinelandii generate alginates with different amounts of alternating structures and/or G-block lengths (Ertesvag et al., 1999). The molecular factors determining the molecular mass of the alginate remain largely unknown, but it has been suggested that it is the result of the polymerase and/or lyase activities on the polymer. In A. vinelandii, the existence of five alginate lyases showing different sequence cleavage specificity and cellular locations have been reported (Gimmestad et al., 2009; Trujillo-Roldán et al., 2003). The periplasmic AlgL protein is involved in the biosynthesis of the polysaccharide, while the extracellular AlgE7 (a bifunctional alginate lyase and C-5 epimerase) and AlyA3 enzymes are involved in the release of the polymer from the cell surface and in the rupture of the cyst coat during germination, respectively. The function of the lyases AlyA1 and AlyA2 remains unknown. However, AlyA2 activity was shown to be essential for vegetative growth (Gimmestad et al., 2009).

The $\operatorname{alg} D$ gene encodes the key enzyme catalyzing the generation of the alginate monomer GDP-mannuronic acid (for a recent review see Galindo et al., 2007). Expression of algD is highly controlled by several global regulators such as the stress response sigma factor AlgU and the signalling transduction cascade conformed by the two-component system GacA/GacS and the stationary growth phase sigma factor RpoS protein, which also positively control PHB synthesis (Castañeda et al., 2000; 2001). A. vinelandii mutants have been constructed with the aim of generating alginates with different physicochemical properties. An algL mutant was shown to produce an alginate with a molecular mass higher than that of the wild type strain (Trujillo-Roldan et al., 2003). Furthermore a mutation in the algF gene, encoding one of the subunits of the $O$-acetylase complex, resulted in the production of a non-acetylated alginate, similar to that of algal origin (Vazquez et al., 1999). As the polymers PHB and alginate compete for the supplied carbon source we generated mutants with a total blockade in PHB synthesis and in which the production of alginate was increased several fold. The contrary was also true for the production of PHB as a total blockade in the synthesis of alginate increased the accumulation of PHB (Segura et al., 2003b).

\subsection{Biosynthesis of PHAs by A. vinelandii}

$\mathrm{PHB}$ in A. vinelandii, as in most bacteria, is synthesized in three steps from acetyl-CoA (Figure 2; Manchak \& Page 1994). $\beta$-Ketothiolase catalyzes the first reaction, i.e. the condensation of two molecules of acetyl-CoA to form acetoacetyl-CoA. This product is subsequently reduced by an NADPH dependent acetoacetyl-CoA reductase to stereoselectively produce (R)- $\beta$-hydroxybutyryl-CoA. Finally, PHB synthase catalyzes the polymerization of (R)- $\beta$-hydroxybutyryl-CoA releasing free CoA.

In $A$. vinelandii, the genes coding for these enzymes are contained in the PHB biosynthetic operon phbBAC, which codes for the acetoacetyl-CoA reductase, $\beta$-ketothiolase, and PHB synthase respectively (Peralta-Gil et al., 2002; Segura et al., 2000, 2003a). In the same DNA region, other genes related to PHB synthesis were also found: $p h b R$, which codes for a transcriptional regulator; $p h b P$, a putative granule-associated protein; and $p h b F$, a putative regulator of $p h b P$ (Peralta-Gil et al., 2002; Segura et al., 2003a). 
When $A$. vinelandii UWD is grown on medium supplemented with n-alkanoates, such as valerate, heptanoate or nonanoate, a copolymer of poly(Hydroxybutyrate-CoHydroxyvalerate) (PHBV) is synthesized (Page et al., 1992). The recent analysis of the $A$. vinelandii genome sequence (Setubal et al., 2009) demonstrated the presence of phaJ, a gene coding for a $(D)$-specific enoyl-Coenzyme A hydratase that is responsible for the channeling of enoyl-CoA derivatives from the fatty acid oxidation pathway to PHAs synthesis in several pseudomonads (Fukui et al., 1998). Thus, this enzyme would be producing the hydroxyvalerate precursors for PHBV synthesis in A. vinelandii (Figure 2).

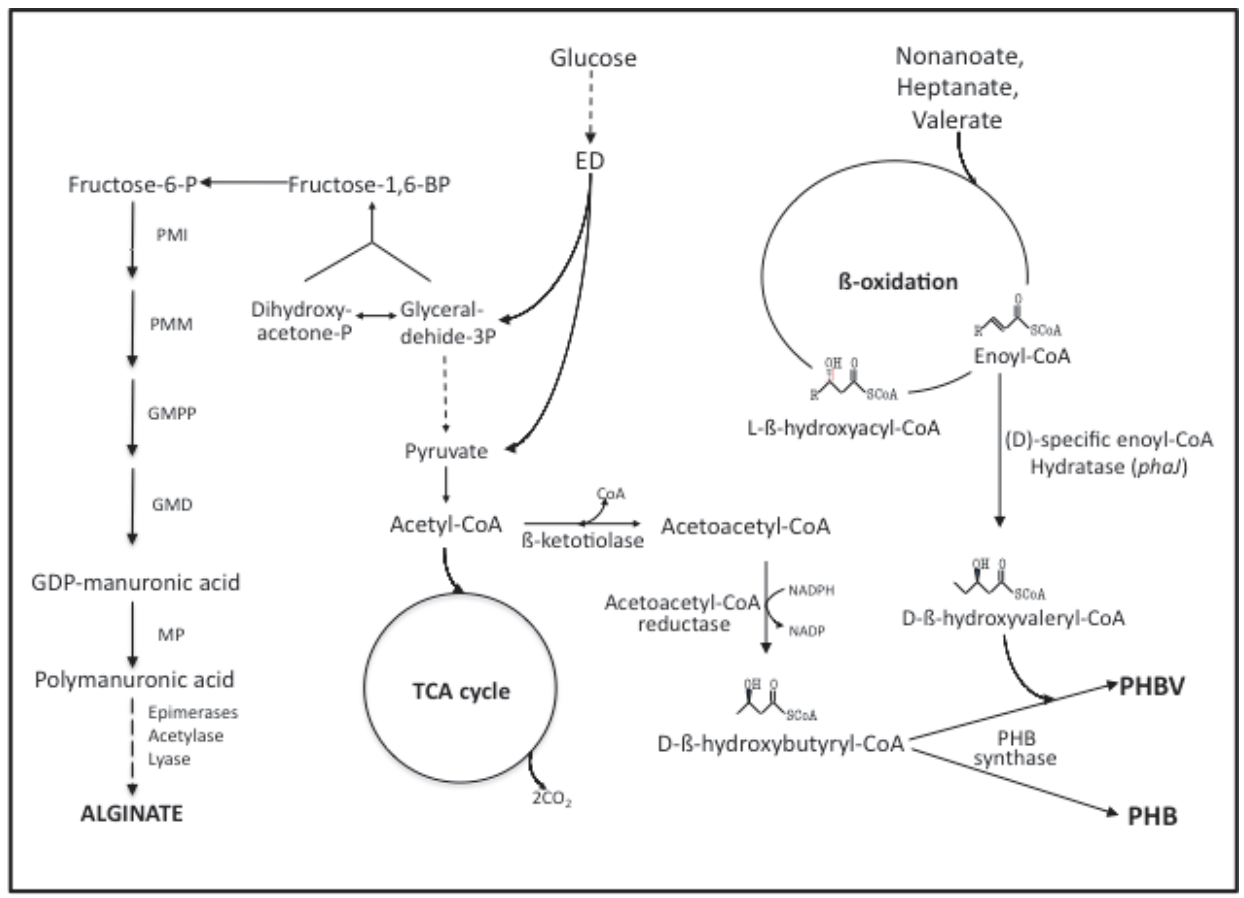

Fig. 2. Metabolic pathways involved in the synthesis of alginate and PHAs in A. vinelandii. PMI, phosphomannose isomerase; PMM, phosphomannose mutase; GMPP, guanosine diphosphomannose pyrophosphorylase; GMD, GDP-mannose dehydrogenase; MP, mannuronate polymerase; ED, Entner-Doudoroff pathway.

The control of PHB biosynthesis in Azotobacter was one of the first to be studied (Senior et al., 1972; Senior \& Dawes, 1971, 1973). The main condition triggering PHB synthesis is oxygen limitation, which leads to high concentrations of NADH and NADPH, that in turn inhibit TCA cycle enzymes, increasing the concentration of acetyl-CoA available for PHB biosynthesis (Manchak \& Page, 1994; Senior et al., 1972; Senior \& Dawes, 1973).

The regulation of $\mathrm{PHB}$ synthesis in $A$. vinelandii is complex and additional regulatory systems are involved. PhbR, a regulator of the AraC family of transcriptional regulators, activates transcription of the $p h b B A C$ operon, and the stationary growth phase sigma factor RpoS is involved in the control of transcription of $p h b R$ (Peralta-Gil et al., 2002). The nitrogen-related phosphotransferase system (PTSNtr), formed by proteins EINtr, Npr, and 
IIANtr regulates PHB synthesis through a phosphorelay from phosphoenolpyruvate, where the IIANtr protein acts as negative regulator of PHB synthesis in its non-phosphorylated state (Segura \& Espin, 1998; Noguez et al., 2008). It has also been reported that the FNR-like regulatory protein called CydR (Wu et al., 2001) and the iron-regulatory small RNA named ArrF (Pyla et al., 2009) control PHB synthesis in response to the redox state of the cell (oxygen), and the availability of iron respectively.

\section{Fermentation parameters affecting the production and the composition of alginate}

For several decades the synthesis of alginate and PHB by A. vinelandii has been the subject of study, either in batch (Clementi et al., 1997; Page \& Cornish 1993; Parente et al., 2000; Peña et al., 2000,2011; Sabra et al., 1999; Trujillo-Roldán et al., 2004), continuous (Díaz-Barrera et al., 2009, 2010; Sabra et al., 2000), fed batch cultures (Chen \& Page, 1997; Mejía et al., 2010; Priego-Jiménez et al., 2005) and systems with immobilized cells in membrane reactors (Saude \& Junter, 2002). In the following sections we will describe and discuss the most recent advances regarding the influence of fermentation parameters, which determine the production and composition of alginate and PHAs.

\subsection{Influence of the dissolved oxygen tension (DOT) and the oxygen transfer rate (OTR) on the quantity and quality of alginate}

Many studies have shown that aeration and mixing are critical parameters for optimizing the production of microbial polysaccharides (Galindo et al., 2007). It is known that under low dissolved oxygen tension (DOT), the organism accumulates the intracellular storage polymer, PHB; whereas at high DOT, A. vinelandii uses the carbon source mainly for biomass production. Efficient conversion of sucrose to alginate is achieved only if the oxygen is accurately controlled between 1 and $10 \%$ of oxygen saturation (Parente et al., 2000; Peña et al., 2000; Sabra et al., 2000; Trujillo-Roldán et al., 2003). The DOT also affects the composition and molecular mass of the alginate produced by $A$. vinelandii. Studies in bioreactor, under oxygen controlled conditions (Peña et al., 2000; Sabra et al., 2001; TrujilloRoldán, 2004), indicate that the mean molecular mass (MMM) of the polymer, is strongly influenced by the DOT and the stirring speed of the culture. For example, in cultures conducted at low agitation speed $(300 \mathrm{rpm})$ and DOT of $5 \%$ the MMM of the polymer reached a maximum of $680 \mathrm{kDa}$. In contrast, at high agitation speed (700 rpm), the MMM increased to a plateau at low DOT (1-3\%) and then decreased at higher DOT (5 \%) (Peña et al., 2000). On the other hand, Sabra et al., (2000) reported that in phosphate-limited continuous culture, both the MM and the L-guluronic acid content increased with the DOT, reaching a maximal $\mathrm{MM}$ of $800 \mathrm{kDa}$ and a guluronic acid content of $50 \%$ in the cultures conducted at $10 \%$ of air saturation. Those authors proposed that under nitrogen- fixing conditions, the bacterium builds a slimy layer or alginate capsule around the cells, to overcome the oxygen stress and to protect the nitrogenase system, causing a decrease in alginate biosynthesis.

A. vinelandii is known for its high respiratory activity (Post et al., 1983) and in cultures without DOT control, the oxygen transfer becomes the limiting factor for growth. Without DOT control, the cultures operate at DOT near zero. Under this condition, a parameter that has been used for studying alginate production is the oxygen transfer rate (OTR). In this line, Díaz-Barrera et al., $(2007,2009)$ reported that the alginate yield and the MMM of the 
polymer were linked to the OTR of the culture. They found that the MMM of the alginate increased as OTR $\mathrm{max}_{\max }$ decreased, observing that the MMM obtained at $3.0 \mathrm{mmol} \mathrm{L}^{-1} \mathrm{~h}^{-1}$ was 7.0 times higher $(1560 \mathrm{kDa})$ than at $9.0 \mathrm{mmol} \mathrm{L}^{-1} \mathrm{~h}^{-1}(220 \mathrm{kDa}$; Figure 3). It is important to quote that in previous reports the cultures were oxygen limited and under such conditions the carbon source was only partially oxidized, which forced the cells to follow anaerobic pathways with the consequent production of PHB.

More recently, Lozano et al., (2011) reported a study about the evolution of the MMM of the alginate produced by A. vinelandii ATCC 9046 in terms of the maximum oxygen transfer rate $\left(\mathrm{OTR}_{\max }\right)$ in cultures where the dissolved oxygen tension (DOT) was kept constant. An increase in the agitation rate (from 300 to $700 \mathrm{rpm}$ ) caused a significant increase in the OTR $_{\max }$ (from 17 to $100 \mathrm{mmol} \mathrm{L}^{-1} \mathrm{~h}^{-1}$ for DOT of $5 \%$, and from 6 to $70 \mathrm{mmol} \mathrm{L}^{-1} \mathrm{~h}^{-1}$ for DOT of $0.5 \%$ ). This increase in the OTR $\mathrm{Tmx}_{\max }$ improved alginate production, as well as the specific alginate production rate. In contrast, the mean molecular mass (MMM) of the alginate isolated from cultures developed under non-oxygen limited conditions increased by decreasing the OTR $R_{\max }$, reaching a maximum of $550 \mathrm{kDa}$ at an OTR $\mathrm{max}_{\max } 17 \mathrm{mmol} \mathrm{L}^{-1} \mathrm{~h}^{-1}$. However, in the cultures developed under oxygen limitation $(0.5 \%$ DOT), the MMM of the polymer was practically the same (around $200 \mathrm{kDa}$ ) at 300 and $700 \mathrm{rpm}$ and it remained constant throughout the cultivation (Lozano et al., 2011).

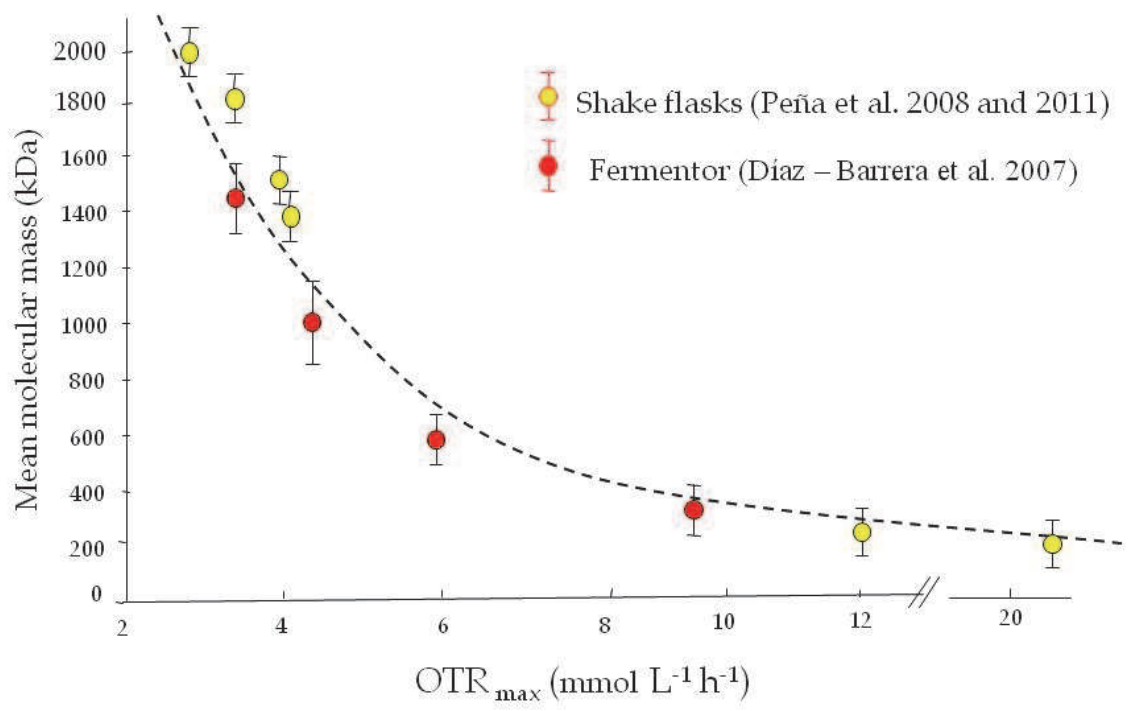

Fig. 3. Mean molecular mass of alginate as a function of the oxygen transfer rate in cultures of $A$. vinelandii in shake flasks and stirred fermentor.

\subsection{Influence of the medium components}

It is widely known that the components of the culture medium play an important role in the production of alginate by $A$. vinelandii. Most studies have focused on assessing the influence of calcium, phosphate and nitrogen on alginate yield and its molecular mass (MM) (Parente et al., 2000; Sabra et al. 1999). Sabra et al., (1999) found that an excess of phosphate in the culture medium (400 $\left.\mathrm{mg} \mathrm{L}^{-1}\right)$ caused a decrease in alginate yield. In the case of nitrogen the 
results reported are contradictory, probably because the strain and medium composition used were different (Clementi, 1997; Sabra et al., 2001). Recently, Zapata-Vélez \& TrujilloRoldán (2010) reported that in cultures of A. vinelandii in shake flasks, the best nitrogen sources for alginate production were peptone, tryptone, and yeast extract, yielding a maximal alginate concentration of $4.0 \pm 0.4 \mathrm{~g} \mathrm{~L}^{-1}$. Those authors found that the highest MMM was obtained in cultures grown with peptone $(1,520 \pm 110 \mathrm{kDa})$, whereas cultures grown with yeast extract, tryptone, ammonium acetate, and ammonium sulphate, showed values between 1,400 and 1,100 $\mathrm{kDa}$. On the other hand, a lower MMM was obtained under $\mathrm{N}_{2}$ fixing conditions $(625 \pm 110 \mathrm{kDa})$.

Our group reported the influence of (3N-morpholino)-propane-sulfonic acid (MOPS), a component used in the medium to keep a constant $\mathrm{pH}$, on the quality of the alginate in terms of the chemical composition and rheological behaviour of alginate-reconstituted solutions (Peña et al., 2006). This compound had an important effect on the acetyl content and physicochemical properties of this polymer. A two-fold higher acetylation degree of alginate was obtained when $13.6 \mathrm{mM}$ MOPS was supplemented to the medium. The higher acetylation resulted in greater viscosity of the alginate solutions, but it exhibited less pronounced pseudoplastic behaviour. These changes in the functional properties of the polymer can have great value in terms of specific applications of alginate in food and pharmaceutical fields.

\subsection{Effect of the specific growth rate}

Another important culture parameter for the synthesis of alginate is the specific growth rate (Díaz-Barrera et al., 2009, 2010; Priego-Jiménez et al., 2005). Priego-Jiménez et al., (2005) using exponentially fed-batch cultures, found that the specific growth rate of $A$. vinelandii negatively affects the $\mathrm{MM}$ of the alginate and to some extent, the alginate/biomass and alginate/sucrose ratio. This effect was particularly pronounced at very low specific growth rates $\left(0.03 \mathrm{~h}^{-1}\right)$, where the $\mathrm{Y}_{\mathrm{P} / \mathrm{X}}, \mathrm{Y}_{\mathrm{P} / \mathrm{S}}$ and the MMM were up to 2.3, 10 and 14 times higher, respectively, than those obtained at a specific growth rate of $0.21 \mathrm{~h}^{-1}$ (the value found in conventional batch cultures). More recently, Díaz-Barrera et al., (2010) reported, in chemostat cultures, that the alginate MM increased from 800 to $1800 \mathrm{kDa}$ when the dilution rate increased from 0.05 to $0.1 \mathrm{~h}^{-1}$ at a low inlet sucrose concentration $\left(5 \mathrm{~g} \mathrm{~L}^{-1}\right)$. In contrast, at high sucrose concentration, the MM increased from 1230 to $2500 \mathrm{kDa}$ when the dilution rate, and therefore, the specific growth rate were decreased in the same range. According to the authors, this behaviour is linked to changes in the specific sucrose uptake rate (Díaz-Barrera et al., 2010).

\section{Parameters that affect PHAs production in A. vinelandii}

Commercial production of PHAs requires not only high yields and productivities, but also a well defined chemical composition. Fermentation parameters affect the amount of PHAs produced by Azotobacter, and their chemical characteristics, such as the kind of polymer produced (PHB homopolymer or PHBV heteropolymer); the MM; and finally, the monomer ratio and distribution along the PHA heteropolymer chain.

PHAs production in different organisms is induced under nutrient limitation (Verlinden et al., 2007). For Azotobacter species, oxygen limitation is the most efficient way to induce PHB production (Galindo et al., 2007; Senior \& Dawes, 1971, 1973; Verlinden et al., 2007). Besides 
oxygen limitation, changes in the carbon and nitrogen sources can affect PHB biosynthesis by Azotobacter (Myshkina et al., 2008; Page, 1992). Also, the addition of alkanoates to the medium allows the synthesis of PHAs with different monomer composition (Myshkina et al., 2010; Page et al., 1992).

\subsection{Oxygen limitation}

When Azotobacter grows under oxygen limitation there is a reduction in the activity of the tricarboxylic acid cycle (TCA), and the molecules of acetyl-CoA are channeled to PHB production, and the synthesis of PHB acts like an electron sink (Page \& Knosp, 1989; Senior et al., 1972). The positive effect of oxygen limitation on PHB production (based on yield and PHB content), has been reported for $A$. vinelandii in batch cultures, using wild type strains UW (Page \& Knosp, 1989) and ATCC9046 (Peña et al., 2011), and the PHB overproducer mutant strain UWD (Page \& Knosp, 1989). Changes in oxygen concentration have been successfully used in fed batch cultures of A. vinelandii UWD (Chen \& Page, 1997; Page et al., 2001). Chen \& Page (1997), enhanced biomass production of this strain using high aeration during the first stage of the culture and then, at the second stage, aeration was lowered, promoting PHB formation. At the end of the culture, PHB concentration reached $36 \mathrm{~g} \mathrm{~L}^{-1}$ of PHB, in contrast to $25 \mathrm{~g} \mathrm{~L}^{-1}$ of PHB reported by Page \& Cornish (1993) in fed-batch cultures without aeration changes.

On the other hand, there are few reports related to the effect of oxygen on the composition of the PHB produced by Azotobacter. Quagliano \& Miyazaki (1997) observed in fermentations of $A$. chroococcum $6 \mathrm{~B}$ that changes in the aeration rate from 0.5 to $2.5 \mathrm{vvm}$ could negatively impact the molecular weight of the PHB with a 10 fold decrease from 1100 to $111 \mathrm{kDa}$. Myshkina et al., (2008) observed, in cultures of A. chroococcum 7B in shake flasks, that the MM increased from 1480 to $1670 \mathrm{kDa}$ when the agitation rate decreased from 250 to $190 \mathrm{rpm}$. In contrast, the yields of $\mathrm{PHB}$ ( $\left.\mathrm{Y}_{\mathrm{PHB} / \text { Biomass }}\right)$ at both agitation rates were the same $\left(0.75 \mathrm{~g}_{\text {PHB }} \mathrm{g}^{-1}\right.$ biomass $)$. These authors also evaluated the effect of strict microaerobic and anaerobic conditions during stationary phase, on PHB yield and on its MM. Under these conditions, the PHB content decreased to 2.6 and $1.7 \mathrm{~g} \mathrm{~L}^{-1}$, respectively, but the $\mathrm{MM}$ increased, reaching $2215 \mathrm{kDa}$ at the strict anaerobic condition (Myshkina et al., 2008).

\subsection{Medium composition: carbon and nitrogen sources}

The high production cost is the main limiting factor for the use of PHAs for commercial purposes. An alternative to reduce costs is the use of cheaper feedstock (Page, 1992). Several attempts have been made to improve the culture media composition which depends on the microorganism (Table 2). Although Azotobacter is a nitrogen fixing bacteria, addition of a fixed nitrogen source can improve PHAs production. Quagliano \& Miyasaki (1997), found that increasing the C:N ratio improved PHB yields, although the MM of the polymer dropped eight fold. Page \& Cornish (1993) observed that organic nitrogen sources like fish peptone improved PHB production. In addition to the use of low cost nitrogen sources, the use of low price carbon sources is a good alternative to reduce production costs (Page, 1992; Verlinden et al., 2007). Page (1992) found that in shake flasks cultures the addition of $0.5 \%$ $(\mathrm{P} / \mathrm{V})$ of beet molasses, increased the PHAs content in $A$. vinelandii UWD to $7 \mathrm{~g} \mathrm{~L}^{-1}$, in contrast to the $1 \mathrm{~g} \mathrm{~L}^{-1}$ obtained when using sucrose at $2 \%(\mathrm{P} / \mathrm{V})$ as a sole carbon source. Although beet molasses were the best carbon source, this strain was also able to grow and produce PHAs using cane molasses, malt extract or corn syrup. However, Myshkina et al., (2008) observed that for A. chroococcum 7B, molasses did not improve growth or PHB 
production, while the best PHB yields were obtained with commercial sugar and vinasses. These authors also reported that the MM of the PHB could be affected by the carbon source, reaching the highest $\mathrm{MM}$ when using glucose, food sugar or starch $(1660,1490$ and 1310 $\mathrm{kDa})$.

\begin{tabular}{|c|c|c|c|c|c|c|c|}
\hline Strain & $\begin{array}{c}\text { Carbon } \\
\text { source }\end{array}$ & $\begin{array}{c}\text { Nitrogen } \\
\text { source }\end{array}$ & PHB (gL-1) & $\mathrm{Y}_{\mathrm{P} / \mathrm{S}}$ & $\begin{array}{c}\text { Mw } \\
(\mathrm{kDa})\end{array}$ & $\begin{array}{l}\text { Type of } \\
\text { culture }\end{array}$ & $\begin{array}{c}\text { Referenc } \\
\text { e }\end{array}$ \\
\hline $\begin{array}{c}\text { A. } \\
\text { vinelandii } \\
\text { UWD }\end{array}$ & $\begin{array}{c}\text { Glucose }(1 \%) \\
\text { and acetate } \\
(15 \mathrm{mM})\end{array}$ & $\mathrm{NH}_{4}^{+}$ & 2.37 & 0.25 & N.D & Flasks & $\begin{array}{c}\text { Page \& } \\
\text { Knosp, } \\
1989\end{array}$ \\
\hline $\begin{array}{c}\text { A. } \\
\text { vinelandii } \\
\text { UWD }\end{array}$ & $\begin{array}{l}\text { Beet } \\
\text { Molasses } \\
(5 \%) \text { and } \\
\text { sucrose }(2 \%)\end{array}$ & $\mathrm{NH}_{4}{ }^{+}$ & 7 & 0.35 & N.D & Flasks & Page, 1992 \\
\hline $\begin{array}{c}\text { A. } \\
\text { vinelandii } \\
\text { UWD }\end{array}$ & $\begin{array}{c}\text { Glucose }(5 \%) \\
\text { acetate } \\
(15 \mathrm{mM})\end{array}$ & $\begin{array}{c}\mathrm{NH}_{4}{ }^{+} \\
\text {Fish peptone } \\
(1 \%)\end{array}$ & 25 & 0.65 & 1700 & $\begin{array}{l}\text { Fed batch } \\
\text { culture }\end{array}$ & $\begin{array}{c}\text { Page \& } \\
\text { Cornish, } \\
1993\end{array}$ \\
\hline $\begin{array}{c}\text { A. } \\
\text { chroococcum } \\
7 \mathrm{~B}\end{array}$ & Glucose (4\%) & ---- & 4 & 0.1 & 1660 & Flasks & $\begin{array}{l}\text { Myshkina } \\
\text { et al., } 2008\end{array}$ \\
\hline $\begin{array}{c}\text { A. } \\
\text { chroococcum } \\
7 \mathrm{~B}\end{array}$ & $\begin{array}{c}\text { Glucose }(2 \%) \\
\text { Acetate } \\
(20 \mathrm{mM})\end{array}$ & ----- & 4 & 0.2 & 1100 & Flasks & $\begin{array}{l}\text { Myshkina } \\
\text { et al., } 2008\end{array}$ \\
\hline $\begin{array}{c}\text { A. } \\
\text { chroococcum } \\
7 \mathrm{~B}\end{array}$ & $\begin{array}{c}\text { Molasses } \\
(4 \%) \\
\text { Sucrose }(2 \%)\end{array}$ & ----- & 1 & 0.05 & N.D. & Flasks & $\begin{array}{l}\text { Myshkina } \\
\text { et al., } 2008\end{array}$ \\
\hline
\end{tabular}

Table 2. PHB production by Azotobacter grown with different sources of carbon and nitrogen.

\subsection{Addition of alkanoates}

For several Azotobacter spp., the addition of alkanoates to the growth media for PHAs production allows the synthesis of polymers with specific composition (Durner et al., 2000; Gónzalez-López et al., 1996; Myshkina et al., 2010; Page et al., 1992; Sun et al., 2007; Zinn et al., 2003). The effect of alkanoates addition is dependent on the strain and its metabolism. In cultures of $A$. vinelandii $\mathrm{UWD}$, the addition of odd alkanoates $\left(\mathrm{C}_{5}-\mathrm{C}_{9}\right)$ allowed the biosynthesis of the copolymer PHBV. Although there was copolymer production using the three different substrates (valerate, heptanoate and nonaoate), the highest proportion of HV was achieved with valerate (Page et al., 1992).

For A. chroococcum the biosynthesis of PHBV by addition of not only five carbon valeric acid but of other organic acids (propanoic and hexanoic), was reported. However the best yields and the highest HV content were obtained with valerate (Myshkina et al., 2010). The addition of alkanoates with more than five carbons to Azotobacter cultures did not allow biosynthesis of hydroxyalkanoates of a higher monomer chain length (Myshkina et., al 2010; Page et al., 1992). Although Azotobacter and Pseudomonas are genetically related (Setubal et al., 2009), the PHAs metabolism in Azotobacter differs completely from that observed in most Pseudomonas species which are efficient producers of mcl-PHAs (Durner et al., 2000; Hartmann et al., 2005; Sun et al., 2007). However, the close genetic relationship between Pseudomonas and $A$. vinelandii could be useful for genetic improvement of $A$. vinelandii 
strains for the biosynthesis of mcl-PHAs, as has been successfully reported for E. coli (Sun et al., 2007; Verlinden et al., 2007).

\section{Scaling up of alginate and PHAs production}

Trying to reproduce in agitated tank the results obtained in plates or in shake flasks, is troublesome and the variables involved are poorly understood. This is particularly important, because the MM of the polymer drops dramatically when the alginate process is scaled up from shake flasks to fermentors (Peña et al., 1997, 2000). Both, the power input $(\mathrm{P} / \mathrm{V})$ and the oxygen transfer rate (OTR), have been used as scaling up parameters (Peña et al., 2008; Reyes et al., 2003). Recently, our group has studied both the evolution of the specific power consumption and oxygen transfer rate, occurring in shake flasks cultures of A. vinelandii (Peña et al., 2007).

These studies have revealed that the power consumption increased exponentially during the course of the fermentation (up to $1.4 \mathrm{~kW} \mathrm{~m}^{-3}$ ) due to an increase in the viscosity of the culture broth. Taking these data as a starting point, a scale-up strategy based on the evolution of the power input observed in shake flasks has been evaluated, trying to reproduce in a stirred fermentor culture the MMM of the alginates obtained in shake flasks (Peña et al., 2008). Simulating the evolution of the power input in $14 \mathrm{~L}$ fermentors, allowed us to reproduce the MMM and molecular mass distributions of the alginate obtained in shake flasks (Figure 4), a situation that had not been possible to achieve before using other criteria (i.e., initial power input (Reyes et al., 2003)).
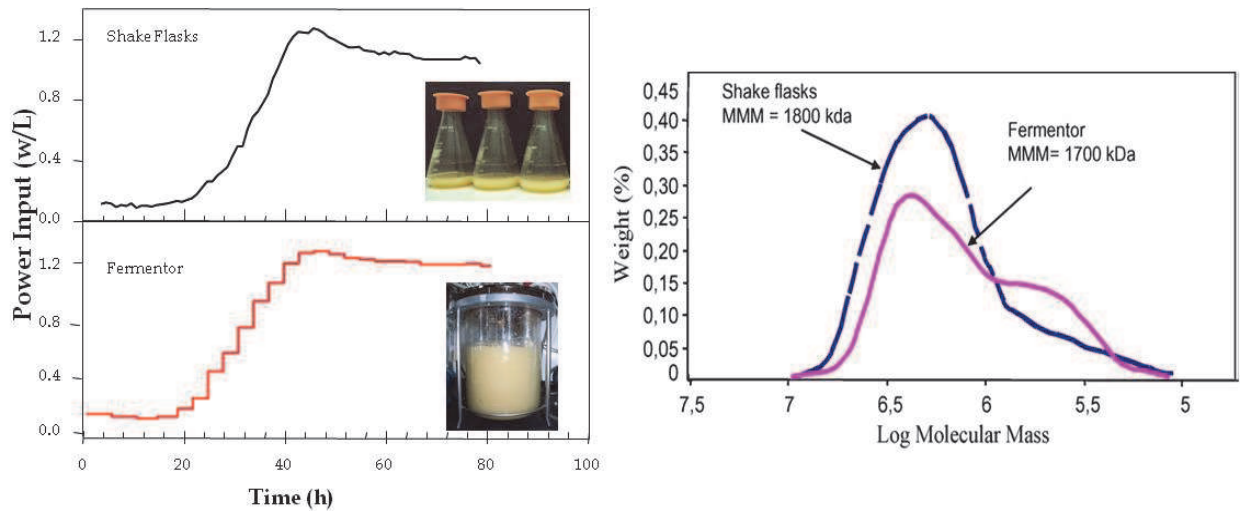

Fig. 4. Scaling-up of alginate production using the evolution of power input as a criterion.

Currently PHAs bacterial production, at industrial scale, is mainly conducted using the strain $C$. necator, until now the most cost-effective fermentative process for the copolymer PHBV (Verlinden, 2007; Wang et al., 2011). In addition, several species of Pseudomonas have been described as potential producers of mcl-PHAs (Durner et al., 2000; Hartmann et al., 2005; Sun et al., 2007; Wang et al., 2011). For both fermentation processes the scaling up strategies have focused not only on increasing biomass and polymer content using low cost feedstock, but also on improving chemical properties of the biopolymer. The main strategies proposed in this line are related to the use of fed batch and continuous cultures (Sun et al., 2007; Verlinden et al., 2007;). The PHAs production is usually operated as fed batch cultures, 
with an initial growth phase in rich medium in order to obtain a high cell density culture, followed by a product accumulation phase usually under substrate limiting conditions (Verlinden et al. 2007; Sun et al., 2007). It is worthy to point out that for fed batch cultivations it is important to define the composition of the media used for starting the culture, the feeding composition, the type of limitation used for inducing PHA synthesis, and the time at which the feeding should be started. The adequate selection of these parameters can improve the yields and composition of the PHA produced.

Fed batch cultures of $A$. vinelandii UWD using beet molasses have successfully improved PHAs content from $7 \mathrm{~g} \mathrm{~L}^{-1}$ obtained in flasks, to up to $25-36 \mathrm{~g} \mathrm{~L}^{-1}$ in fed batch cultures, reaching a maximum yield of $0.65 \mathrm{~g}_{\text {PHA }} \mathrm{g}^{-1}$ Carbon source (Chen \& Page, 1997; Page et al., 2001). Continuous fermentation is an alternative to increase PHAs productivity (Sun et al., 2007). These fermentations have been successfully used to improve mcl-PHAs production parameters with Pseudomonas (Sun et al., 2007) and scl-PHAs with C. necator (Zinn et al., 2003). Using C. necator DSM 428, Zinn et al., (2003) evaluated the PHBV copolymer production under dual $(\mathrm{C}, \mathrm{N})$ limitation in chemostat cultures, obtaining controlled composition of the polymer in the range of $0-62 \mathrm{~mol} \% \mathrm{HV}$. The cultivations in chemostat allowed a constant production of $\mathrm{PHB} / \mathrm{HV}$ and an accurate control of the polymer composition.

In the case of mcl-PHAs production, Hartmann et al., (2005) evaluated chemostat cultures of Pseudomonas putida GPo1 under dual (C, N) limitation. They found, that the monomeric composition of mcl-PHAs was independent of the C:N ratio in the feed media, but it was dependent on the dilution rate. They also found that at low dilution rates, the fraction of aliphatic monomers in the mcl-PHAs was slightly higher than at high dilution rates.

\section{Design of novel processes to improve alginate and PHA production}

Alginate production by fermentation using the $A$. vinelandii bacterium could be a feasible strategy; however, polymer concentrations in batch cultures reported so far are very low, with maximum concentrations of alginate in the range of 3-5 g L-1 (Parente et al., 2000; Peña et al., 2000; Sabra et al., 2000). It is important to point out that the final alginate concentration is the most important parameter in determining the economics of the process, as it is related to the recovery cost, especially during the precipitation step (Peña et al., 2008). Several fermentation strategies have been reported in the literature with the aim of improving the quantity and/or quality of the alginate (Asami et al., 2004; Cheze-Lange et al., 2002; Mejia et al., 2010; Saude \& Junter, 2002). For example, Cheze-Lange et al., (2002) reported the advantages of continuous production of bacterial alginate by $A$. vinelandii, coupled to a system of membranes of varying nominal pore sizes. According to these authors, the yields of alginate with respect to sucrose were significantly higher compared to the batch process. However, the MM of the polymer and the polydispersity were very similar to those of the alginate obtained from batch experiments. Asami et al., (2004) found that the productivity and the fraction of GG-blocks of the alginate produced by A. vinelandii in a bubble column were higher than those obtained in shake flasks. They observed that the production of GG-blocks in the late exponential growth phase was higher than that obtained in the stationary phase. However, the authors did not explain the reasons for the difference in the fraction of GG blocks under varying conditions.

Our research group has carried out studies in fed-batch and multistage fermentation processes (Mejía et al., 2010; Priego-Jiménez et al., 2005) that are able to achieve high 
biomass concentration, in order to take advantage of the higher specific-alginate production capacities of mutant such as the AT6 strain. Employing a high oxygen concentration (10\%) allowed obtaining a maximum biomass concentration of $7.5 \mathrm{~g} \mathrm{~L}^{-1}$ in the first stage of the cultivation. In the second stage, the cultures were limited by oxygen (oxygen close to $0 \%$ ) and fed with a sucrose solution at high concentration. Under those conditions, the growth rate decreased considerably and the cells used the carbon source mainly for alginate biosynthesis, obtaining a maximum concentration of $9.5 \mathrm{~g} \mathrm{~L}^{-1}$, after $50 \mathrm{~h}$ of cultivation. Alginate concentration obtained from the AT6 strain was two fold higher than that obtained using the wild-type strain (ATCC 9046) and was the highest reported in the literature (Mejía et al., 2010).

Most of the studies using Azotobacter spp. for PHA production have been implemented using batch cultures. Because PHAs are intracellular products and their synthesis occurs under growth limiting conditions, like oxygen limitation, fed-batch fermentation or multistage cultures have been the methods used to achieve high cell densities containing the highest possible amount of PHA with several PHA producers (Akaraonye et al., 2010). On the other hand, continuous cultivation is an interesting alternative strategy because a high productivity can be reached, especially for strains with a high specific growth rate (Akaraonye et al., 2010). However, it is difficult to balance biomass concentration, PHAs content and productivity, because changes in the dilution rate can have opposite effects on cell growth and PHAs synthesis. This is due to the requirement for a nutrient limitation to induce polymer synthesis, at growth rates below the maximum specific growth rate. The ability to produce PHAs under non limiting growth conditions of some A. vinelandii strain could represent an advantage to establish continuous culture processes (Page \& Knosp, 1989).

Two-stage continuous cultures can help establishing a good growth/PHAs synthesis compromise. Jung et al., (2001) used a two-stage continuous cultivation system with two fermentors connected in series, producing cells at a specific growth rate in the first compartment, and establishing conditions to accumulate PHA at higher rates in a second compartment, with a relatively long residence time. Dilution rates of $0.21 \mathrm{~h}^{-1}$ in the first fermentor and $0.16 \mathrm{~h}^{-1}$ in the second fermentor yielded a volumetric PHAs productivity of $0.06 \mathrm{~g}_{\mathrm{PHA}} \mathrm{L}^{-1} \mathrm{~h}^{-1}$, a high productivity for cultures grown on alkanes.

Processes using cheaper substrates have the potential to lower the production costs of PHAs production, but for the use of some of these substrates additional processing is needed. Cerrone et al., (2010) reported an interesting strategy to simultaneously produce PHB and treat olive mil wastewater using $A$. vinelandii UWD, A. vinelandii ATCC 12387, or A. chroococcum. It consisted on a phase of anaerobic digestion of the olive mil wastewater during $27 \mathrm{~h}$, in order to produce short-chain fatty acids, to later inoculate the Azotobacter strains for the aerobic PHA producing stage. Similar strategies could be implemented for the utilization of other agro-industrial residues allowing the use of cheap substrates and additionally reducing costs by linking PHA production with waste disposal processes.

\section{Down stream processes}

Alginate and PHAs have been proposed for novel applications in pharmaceutical and biomedical fields. However, for these applications it is necessary to ensure products with a high purity, and in most cases with a defined chemical composition. Chemical composition of these polymers can be controlled by the fermentation stage, but their purity will be 
determined by the down stream processing. Moreover, costs and efficiency of purification procedures could affect the whole process feasibility.

The extraction process of alginate from Azotobacter, starts with the supernatant recovery from the fermentation broth by centrifugation. Afterwards, the supernatant is treated with $\mathrm{NaCl}_{2}$, followed by an acidification-hydration step, and finally it is precipitated with isopropanol. This final product could be dried and milled (Sabra \& Zeng, 2009). However, alginates for applications in the biomedical and pharmaceutical fields need to be nonimmunogenic, and this extraction process does not ensure a high purity of the product. The immunogenic response could be due to the presence of polyphenols, endotoxins or proteins (Ménard et al., 2010). With the purpose of removing these impurities Ménard et al., (2010) proposed the introduction of size exclusion chromatography (SEC). Using this method, the authors observed a reduction of up to $90 \%$ of residual protein contaminants in commercial alginate and therefore a decrease in the immunogenicity of the alginate beads prepared. Once that alginate is purified, it could be modified to enhance or change its physicochemical properties, by either chemical (Yang et al., 2011) or enzymatic methods (Morch et al., 2008). Alginate downstream modifications could include, acetylation, addition of aminoacids and/or proteins, deacetylation, epimerization, oxidation, sulfation and copolymerization.

The PHAs extraction processes require the separation of the cells containing the polymer by centrifugation. The recovery of intracellular PHAs could be carried out by solvent extraction using acetone, chloroform, methylene chloride or dichloroethane. Although this method is the most used, it is also expensive and environmentally unfriendly (Verlinden et al., 2007; Yasotha et al., 2006). Besides, several alternative methods have been developed to improve PHAs purification. Enzymatic digestion does not need hazardous solvents and it shows high selectivity. Yasotha et al., (2006) proposed an enzymatic method coupled to an ultrafiltration system and achieved a final PHAs purity of $92.6 \%$ with a recovery of almost $90 \%$. However, this method could be very expensive. Another interesting alternative for PHAs recovery was proposed by Page \& Cornish (1993), using fish peptone like nitrogen source for the growth of $A$. vinelandii. Fish peptone enhanced PHB production and led to the production of pleomorphic and osmotically sensitive cells. They took advantage of this cell fragility to simplify PHAs extraction method using $\mathrm{NH}_{4} \mathrm{OH}$ at $45^{\circ} \mathrm{C}$. With this method $\mathrm{PHB}$ was recovered with a $94 \%$ of purity. Finally, Hejazi et al., (2003), developed a method based on supercritical fluid disruption of the cells using supercritical $\mathrm{CO}_{2}$ at $200 \mathrm{~atm}$, with a PHB recovery of $89 \%$. Although this method also uses organic solvents, it requires less than the traditional extraction method.

\section{Conclusions}

Based on a better understanding of the biosynthesis and regulation of alginate and PHAs in A. vinelandii, as well as on the development of new cell culture systems for biopolymers production, it is possible to propose new fermentation strategies to obtain alginate and PHAs with specific chemical characteristics and more defined material properties. These materials could be used in specific applications in pharmaceutical and biomedical fields. In summary, this chapter has shown that the use of a multidisciplinary approach, integrating molecular and bioengineering aspects, would allow the optimization of both alginate and PHAs production using $A$. vinelandii. 


\section{Acknowledgment}

Financial support of DGAPA-UNAM (grants IN218201, IN216700, and IN221809) and CONACyT (grant 57220, 101643 and 127979) is gratefully acknowledged. The authors acknowledge R. Rodríguez Bahena for his assistance on computer support.

\section{References}

Akaraonye, E.; Keshavarz, T. \& Roy, I. (2010). Production of polyhydroxyalkanoates: the future Green materials of choice. Journal of Chemical Technology and Biotechnology, 85, 732-743.

Aldor, I. \& Keasling, J. (2003). Process design for microbial plastic factories: metabolic engineering of polyhydroxyalkanoates. Current Opinion on Biotechnology, 14, 475483.

Asami, K.; Aritomi, T.; Tan, Y. \& Ohtaguchi, K. (2004). Biosynthesis of polysaccharide alginate by Azotobacter vinelandii in a bubble column. Journal of Chemical Engineering Japan, 37, 1050-1055.

Augst, A.; Joon-Kong, H. \& Mooney, D. (2006). Alginate hydrogels as biomaterials. Macromolecular Bioscience, 6, 623-633.

Banki, M.; Gerngross, T. \& Wood, D. (2005). Novel and economical purification of recombinant proteins: Intein-mediated protein purification using in vivo polyhydroxybutyrate (PHB) matrix association. Protein Sciences, 14(6), 1387-1395.

Barnard, G.; McCool, J.; Wood, D. \& Gerngross, T. (2005). Integrated recombinant protein expression and purification platform based on Ralstonia eutropha. Applied and Environmental Microbiolology, 71, 5735-5742.

Brockelbank, J.; Peters, V. \& Rehm, B. (2006). Recombinant Escherichia coli strain produces a $\mathrm{ZZ}$ domain displaying biopolyester granules suitable for Immunoglobulin $\mathrm{G}$ purification. Applied and Environmental Microbiology, 72(11), 7394-7397.

Campos, M.; Martinez-Salazar, J.; Lloret, L.; Moreno, S.; Núñez, C.; Espín, G. \& SoberonChávez, G. (1996). Characterization of the gene coding for GDP-mannose dehydrogenase $($ algD) from Azotobacter vinelandii. Journal of Bacteriology, 178, 17931799.

Castañeda, M.; Guzmán, J.; Moreno, S. \& Espin, G. (2000). The GacS sensor kinase regulates alginate and poly-beta-hydroxybutyrate production in Azotobacter vinelandii. Journal of Bacteriology, 182, 2624-2628.

Castañeda, M.; Sanchez, J.; Moreno, S.; Nunez, C. \& Espin, G. (2001). The global regulators GacA and sigma(S) form part of a cascade that controls alginate production in Azotobacter vinelandii. Journal of Bacteriology, 183, 6787-6793.

Cerrone, F.; Sánchez-Peinado, M.; Juárez-Jiménez, B.; González-López, J. \& Pozo, C. (2010). Biological teatment of two-phase olive mil wastewater (TPOMW, alpeorujo): Polyhydroxyalkanoates (PHAs) production by Azotobacter strains. Journal of Microbiology and Biotechnology, 20, 594-601.

Chen, G. \& Page, W. (1997). Production of poly- $\beta$-hydroxybutyrate by Azotobacter vinelandii in a two-stage fermentation process. Biotechnology Technology, 11, 347-350.

Chen, G. \& Wu, Q. (2005). The application of polyhydroxyalkanoates as tissue engineering materials. Biomaterials, 26, 6565-6578. 
Chen, G. (2009). A microbial polyhydroxyalkanoates (PHA) based bio-and materials industry. Chemistry Society Reviews, 38, 2434-2446.

Cheze-Lange, H.; Beunard, D.; Dhulster, P.; Guillochon, D.; Caze, A.; Morcellet, M.; Saude, N. \& Junter.; G. (2002). Production of microbial alginate in a membrane bioreactor. Enzyme Microbiology Technology, 30, 656-661.

Clementi, F. (1997). Alginate production by Azotobacter vinelandii. Critical Reviews in Biotechnology, 17, 327-361.

Conway, T. (1992). The Entner-Doudoroff pathway: History, physiology and molecular biology. FEMS Microbiology Reviews, 9, 1-27.

Díaz-Barrera, A.; Peña, C. \& Galindo, E. (2007). The oxygen transfer rate influences the molecular mass of the alginate produced by Azotobacter vinelandii. Applied Microbiology Biotechnology, 76, 903-910.

Díaz-Barrera, A.; Silva, P.; Ávalos, R. \& Acevedo, F. (2009). Alginate molecular mass produced by Azotobacter vinelandii in response to changes of the $\mathrm{O}_{2}$ transfer rate in chemostat cultures. Biotechnology Letters, 31, 825-829.

Díaz Barrera, A.; Silva, P.; Berrios, J. \& Acevedo, F. (2010). Manipulating the molecular weight of the alginate produced by Azotobacter vinelandii in continuous cultures. Bioresource Technology, 101, 9405-08.

Donnan, F. \& Rose, R. (1950). Osmotic pressure, molecular weight, and viscosity of sodium alginate. Canadian Journal Research, 28 (B), 105-113.

Dörig, G. \& Pier G. (2008). Vaccines and immunotherapy against Pseudomonas aeruginosa, Vaccine, 26, 1011-1024.

Draget, I. \& Taylor, C. (2011). Chemical, physical and biological properties of alginates and their biomedical implications. Food Hydrocolloids, 25, 251-256.

Durner, R. ; Witholt, B. \& Egli, T. (2000). Accumulation of Poly R- $\beta$-Hydroxyalkanoates in Pseudomonas oleovorans during growth with octanoate in continuous culture at different dilution rates, Applied and Environmental Microbiology, 66(8), 3408-3414.

Ertesvag, H.; Hoidal, H.; Schjerven, H.; Svanem, B. \& Valla, S. (1999). Mannuronan C-5 epimerases and their application for in vitro and in vivo design of new alginates useful in biotechnology. Metabolic Engineering, 1, 262-269.

Freier, T. (2006). Biopolyesters in Tissue Engineering Applications. Advances in Polymer Science. 203, 1-61.

Fukui, T.; N. Shiomi, \& Y. Doi. (1998). Expression and characterization of (R)-specific enoyl coenzyme A hydratase involved in polyhydroxyalkanoate biosynthesis by Aeromonas caviae. Journal of Bacteriology, 180, 667-673.

Galindo, E.; Peña, C. ; Núñez, C. ; Segura, D. \& Espin, G. (2007). Molecular and bioengineering strategies to improve alginate and polyhydroxyalkanoate production by Azotobacter vinelandii. Microbial Cell Factories, 6, 1-16.

Gimmestad, M.; Ertesvag, H.; Heggeset, T.;Aarstad, O.; Svanem, B. \& Valla, S. (2009). Characterization of three new Azotobacter vinelandii alginate lyases, one of which is involved in cyst germination. Journal of Bacteriology, 191, 4845-4853.

González-López, J. ; Pozo, C. ; Martínez-Toledo, M. ; Rodelas, B. \& Salmeron, V. (1996). Production of polyhydroxyalkanoates by Azotobacter chroococcum $\mathrm{H} 23$ in wasteater from olive oil mills (Alpechin), International Biodeterioration and Biodegradation, 38 (34), 271-276. 
Grage, K.; Jahns, A.; Parlane, N.; Palanisamy, R.; Rasiah, I.; Atwood, J. \& Rehm B. (2009). Bacterial polyhydroxyalkanoate granules: biogenesis, structure, and potential use as nano-/micro-Beads in biotechnological and biomedical applications. Biomacromolecules, 10, 660-669.

Grant, G.; Morris, E.; Rees, D.; Smith, P.; \& Thom, D. (1973). Biological interactions between polysaccharide and divalent cations: the egg box model. FEBS Letters, 32, 195-198.

Hartmann, R. ; Hany, R. ; Pletscher, E. ; Ritter, A. ; Witholt, B. \& Zinn M. (2005). Tailor-made olefinic medium chain lenght poly R-hydroxyalkanoates by Pseudomonas putida Gpo1 : Batch versus chemostat production, Biotechnology and Bioengineering, 93 (4), 737-746.

Hejazi, P. ; Vasheghani-Farahani, E. \& Yamini, Y. (2003). Supercritical fluid disruption of Ralstonia eutrofa for Poly- $\beta$-Hydroxybutyrate recovery, Biotechnology Progress, 19, 1519-1523.

Hernández R. ; Orive G. ; Murua A. ; \& Pedraz J. (2010). Microcapsules and microcarriers for in situ cell delivery, Advanced Drug Delivery Reviews, 62 (7-8), 711-730.

Hoesli, C. ; Raghuram, K. ; Kiang, R. ; Mocinecová, D. ; Hu, X.L ; Johnson, J. ; Lacík, I. ; Kieffer, T. \& Piret, J. (2011). Pancreatic cell immobilization in alginate beads produced by emulsion and internal gelation, Biotechnology and Bioengineering, $108(2), 424-434$.

Hori, Y.; Winans, A.; Huang, C.; Horrigan, E. \& Irvine, D. (2008), Injectable dendritic cellcarrying alginate gels for immunization and immunotherapy. Biomaterials, 29, 36713682.

Hori, Y.; Stern, P. J.; Hynes, R. \& Darrell, J. (2009). Engulfing tumors with synthetic extracellular matrices for cancer immunotherapy. Biomaterials, 30 (35), 6757-6767.

Jahns, A.; Haverkamp, R. \& Rehm, B. (2008). Multifunctional Inorganic-Binding Beads SelfAssembled Inside Engineered Bacteria. Bioconjugate Chemistry, 19 (10), 2072-2080.

Jung, K.; Hazenberg, W.; Prieto, M. \& Witholt, B. (2001). Two-stage continuous process development for the production of medium-chain-length poly(3hydroxyalkanoates). Biotechnology and Bioengineering, 72, 19-24.

Kashef, N.; Behzadian-Nejad, Q.; Najar-Peerayeh, S.; Mousavi-Hosseini, K.; Moazzeni, M. \& Gholamreza E. (2006). Synthesis and characterization of Pseudomonas aeruginosa alginate-tetanus toxoid conjugate. Journal of Medical Microbiology, 55, 1441-1446.

Kennedy, C.; Rudnick, P.; MacDonald, T.; \& Melton, T. (2005). Genus Azotobacter. In: Bergey's Manual of Systematic Bacteriology, G. M. Garrita, 384-401, vol. 2 part B, SpringerVerlag, New York, NY.

Khanna, S. \& Srivastava, A. (2005). Recent advances in microbial polyhydroxyalkanoates. Process Biochemistry, 40, 607-619.

Lee S. (1996). Bacterial Polyhydroxyalkanoates. Biotechnology and Bioengineering 49, 1-14.

Lee, S.; Park, J.; Park, T.; Lee, S.; Lee, S. \& Park, J. K. (2005). Selective Immobilization of Fusion Proteins on Poly(hydroxyalkanoate) Microbeads. Analytical Chemistry, 77, 5755-5759.

Lozano, E.; Galindo, E. \& Peña, C. (2011). The quantity and molecular mass of the alginate produced by Azotobacter vinelandii under oxygen-limited and non oxygen-limited conditions are determined by the maximal oxygen transfer rate $\left(\mathrm{OTR}_{\max }\right)$. Microbial Cell Factories, 10, 1-13. 
Ludwig, B.; Zimmerman, B.; Steffen, A.; Yavriants, K.; Azarov, D.; Reichel, A.; Vardi, P.; Grman, T.; Shabtay, N.; Rote, A.; Evron, Y., Neufeld, T.; Mimon, S.; Ludwig, S.; Brendel, M.; Bornstein, S. \& Barkai, U. (2010). A novel device for islet transplantation providing immune protection and oxygen supply. Hormone Metabolism Research, 42, 918-922.

Lynn, A. \& Hassid, W. (1966). Pathway of alginic acid synthesis in the marine brown alga, Fucus gardneri Silva. Journal of Biological Chemistry, 241, 5284-5297.

Madison, L. \& Huisman, G. (1999). Metabolic Engineering of Poly(3-Hydroxyalkanoates): From DNA to Plastic. Microbiology and Molecular Biology Reviews, 63(1), 21-53.

Manchak, J. \& Page, W. (1994). Control of polyhydroxyalkanoates synthesis in Azotobacter vinelandii strain UWD. Microbiology, 140, 953-963.

Mee, C.; Banki, M. \& Wood, D. (2008). Towards the elimination of chromatography in protein purification: Expressing proteins engineered to purify themselves. Chemical Engineering Journal, 135 (1-2), 56-62.

Mejía, M.; Segura, D.; Espín, G.; Galindo, E. \& Peña, C. (2010). Two stage fermentation process for alginate production by Azotobacter vinelandii mutant altered in poly- $\beta$ hydroxybutyrate (PHB) synthesis. Journal of Applied Microbiology, 108, 55-61.

Ménard, M.; Dusseault, J.; Langlois, G.; Baille, W.; Tam, S.; Yahia, L.; Zhu, X.; \& Hallé, J-P. (2010). Role of protein contaminants in the inmmunogenicity of alginates. Journal of Biomedical Materials Research part B: Applied Biomaterials, DOI:10.1002/jbm.b.31570.

Morch, Y.; Holtan, S.; Donatti, I.; Strand, B. \& Skjak-Braek. (2008). Mechanichal properties of C-5 epimerized alginates. Biomacromolecules, 9, 2360-2368.

Myshkina, V.; Nikolaeva, D.; Makhina, T.; Bonartsev, A.; \& Bonartseva, G. (2008). Effect of growth conditions on the molecular weight of polyhydroxybutyrate produced by Azotobacter chroococcum 7B, Applied Biochemistry and Microbiology, 44 (5), 482-486.

Myshkina, V.; Ivanov, E.; Nikolaeva, D.; Makhina T.; Bonartsev A.; Filatova E.; Ruzhitsky A. \& Bonartseva G. (2010). Biosynthesis of poly- $\beta$-hydroxybutyrate-cohydroxyvalerate copolymer by Azotobacter chroococcum strain 7B. Applied biochemistry and microbiology, 46 (3), 289.296.

Noguez, R.; Segura, D.; Moreno, S.; Hernández, A.; Juárez, K. \& Espín, G. (2008). Enzyme

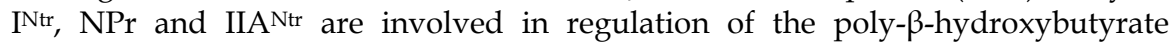
biosynthetic genes in Azotobacter vinelandii. Journal of Molecular Microbiology and Biotechnology 15, 244-254.

Page, W. \& Knosp, O. (1989). Hyperproduction of polyhydroxybutyrate during exponential growth of Azotobacter vinelandii UWD, Applied and Environmental Microbiology, 55(6), 1334-1339.

Page, W.; Manchak, J. \& Rudy, B. (1992). Formation of poly(hydroxybutyrate-cohydroxyvalerate) by Azotobacter vinelandii UWD. Applied and Environmental Microbiology, 58, 2866-2873.

Page, W. (1992). Production of polyhydroxyalkanoates by Azotobacter vinelandii UWD in beet molasses culture, FEMS Microbiology Reviews, 103,149-158.

Page, W. \& Cornish, A. (1993). Growth of Azotobacter vinelandii UWD in Fish Peptone Medium and Simplified Extraction of Poly- $\beta$-hydroxybutyrate. Applied and Environmental Microbiology, 59, 4236-4244. 
Page, W.; Tindale, A.; Chandra, M. \& Kwon E. (2001). Alginate formation in Azotobacter vinelandii UWD during stationary phase and the turnover polyhydroxybutyrate. Microbiology, 147, 483-490.

Parente, E.; Crudele, M.; Ricciardi, A.; Mancini, M.; Clementi F. (2000). Effect of ammonium sulphate concentration and agitation speed on the kinetics of alginate production by Azotobacter vinelandii DSM576 in batch fermentation. Journal of Industrial Microbiology and Biotechnology, 25, 242-248

Peña, C.; Campos, N.; Galindo, E. (1997) Changes in alginate molecular mass distributions, broth viscosity and morphology of Azotobacter vinelandii cultured in shake flasks. Applied Microbiology and Biotechnology, 48, 510-515.

Peña, C.; Trujillo-Roldan, M. \& Galindo, E. (2000). Influence of dissolved oxygen tension and agitation speed on alginate production and its molecular weight in cultures of Azotobacter vinelandii. Enzyme and Microbiology Technology, 27, 390-398.

Peña, C.; Hernandez, L. \& Galindo, E. (2006) Manipulation of the acetylation degree of Azotobacter vinelandii alginate by supplementing the culture medium with 3-(Nmorpholino)-propane-sulfonic acid. Letters of Applied Microbiology, 43, 200-204.

Peña, C.; Peter, C.; Büchs, J. \& Galindo, E. (2007) Evolution of the specific power consumption and oxygen transfer rate in alginate-producing cultures of Azotobacter vinelandii conducted in shake flasks. Biochemical Engineering Journal, 36: 73-80.

Peña, C.; Millán, M. \& Galindo, E. (2008). Production of alginate by Azotobacter vinelandii in a stirred fermentor simulating the evolution power input observed in shake flasks. Processes of Biochemistry, 43, 775-778.

Peña, C.; Galindo, E.; Büchs, J. (2011). The viscosifying power, degree acetylation and molecular mass of the alginate produced by Azotobacter vinelandii in shake flasks are determined by the oxygen transfer rate. Process Biochemistry, 46, 290-297.

Peralta-Gil, M.; Segura, D.; Guzmán, J.; Servin-Gonzalez, L. \& Espin, G. (2002). Expression of the Azotobacter vinelandii poly-beta-hydroxybutyrate biosynthetic phbBAC operon is driven by two overlapping promoters and is dependent on the transcriptional activator PhbR. Journal of Bacteriology, 184, 5672-5677.

Peters, V. \& Rehm, B. (2008). Protein engineering of streptavidin for in vivo assembly of streptavidin beads. Journal of Biotechnology, 134, 266-274.

Pindar, D. \& Bucke, C. (1975). The biosynthesis of alginic acid by Azotobacter vinelandii. Biochemistry Journal, 152, 617-622.

Poole, R. \& Hill, S. (1997). Respiratory protection of nitrogenase activity in Azotobacter vinelandii, roles of the terminal oxidases. Biosciences Reports, 17, 303-317.

Post, E.; Kleiner, D. \& Oelze, J. (1983). Whole cell respiration and nitrogenase activities in Azotobacter vinelandii growing in oxygen controlled continuous culture. Archives of Microbiology, 134, 68-72.

Priego-Jiménez, R.; Peña, C.; Ramírez, O.T.; Galindo, E. (2005). Specific growth rate determines the molecular weight of the alginate produced by Azotobacter vinelandii. Biochemistry Engineering Journal, 25, 187-193.

Pyla, R.; Kim, T.; Silva, J. \& Jung, Y. (2009). Overproduction of poly-beta-hydroxybutyrate in the Azotobacter vinelandii mutant that does not express small RNA ArrF. Applied Microbiology and Biotechnology, 84 (49), 717-724. 
Quagliano, J. \& Miyazaki, S. (1997). Effect of aeration and carbon/nitrogen ratio on the molecular mass of the biodegradable polymer poly- $\beta$-hydroxybutyrate obtained from Azotobacter chroococcum 6B, Applied microbiology and biotechnology, 48, 662-664.

Remminghorst, U. \& Rehm, B. (2006). Bacterial alginates: from biosynthesis to applications. Biotechnology Letters, 28, 1701-1712.

Reyes, C.; Peña, C. \& Galindo, E. (2003). Reproducing shake flasks performance in stirred fermentors: production of alginates by Azotobacter vinelandii. Journal of Biotechnology, 105, 189-198.

Ruth, K.; Grubelnik, A.; Hartman, R.; Egli, T.; Zinn, M.; \& Ren Q. (2007). Efficient production of (R)- $\beta$-hydroxycarboxylic acids by biotechnological conversion of Polyhydroxyalkanoates and their purification. Biomacromolecules. 8(1), 279-286.

Sabra, W.; Zeng, A.; Sabry, S.; Omar, S. \& Deckwer, W-D. (1999). Effect of phosphate and oxygen concentrations on alginate production and stoichiometry of metabolism of Azotobacter vinelandii under microaerobic conditions. Applied Microbiology and Biotechnology, 52, 773-780.

Sabra, W.; Zeng, A.; Lunsdorf, H. \& Deckwer, W-D. (2000). Effect of oxygen on formation and structure of Azotobacter vinelandii alginate and its role in protecting nitrogenase Applied and Environmental Microbiology, 66, 4037-4044.

Sabra, W.; Zeng, A. \& Deckwer, W.D. (2001). Bacterial alginate: physiology, product quality and process aspects. Applied Microbiology and Biotechnology, 56, 315-325.

Sabra, W. \& Zeng, A. (2009). Microbial production of alginates: Physiology and Process Aspects, In: Alginates: Biology and Applications, Bernd H. A. Rehm, 153-173, Microbiology Monographs Vol. 13, Springer Verlag, DOI: 10.1007/978-3-540-926795, Berlín-Heidelberg.

Saude, N. \& Junter, G. (2002). Production and molecular weight characteristics of alginate from free and immobilized-cell cultures of Azotobacter vinelandii. Process Biochemistry 2 (37), 895-900.

Segura, D. \& Espin, G. (1998). Mutational inactivation of a gene homologous to Escherichia coli ptsP affects poly-beta-hydroxybutyrate accumulation and nitrogen fixation in Azotobacter vinelandii. Journal of Bacteriology, 180, 4790-4798.

Segura, D.; Vargas, E. \& Espín, G. (2000). Beta-ketothiolase genes in Azotobacter vinelandii. Gene, 260,113-120.

Segura, D.; Cruz, T. \& Espin, G. (2003a). Encystment and alkylresorcinol production by Azotobacter vinelandii strains impaired in polybeta- hydroxybutyrate synthesis. Archives of Microbiology, 179, 437-443.

Segura, D.; Guzmán, J.; \& Espín, G. (2003b). Azotobacter vinelandii mutants that overproduce poly-beta-hydroxybutyrate or alginate. Applied Microbiology and Biotechnology, 63, 159-163.

Senior, P. \& Dawes, E. (1971). Poly- $\beta$-hydroxybutyrate biosynthesis and the regulation of glucose metabolism in Azotobacter beijerinckii. Biochemistry Journal, 125, 55-66.

Senior, P.; Beech, G.; Ritchie, G. \& Dawes, E. (1972). The role of oxygen limitation in the formation of poly- $\beta$-hydroxybutyrate during batch and continuous culture of Azotobacter beijerinckii. Biochemistry Journal, 128, 1193-1201.

Senior, P. \& Dawes, E. (1973). The regulation of poly- $\beta$-hydroxybutyrate metabolism in Azotobacter beijerinckii. Biochemistry Journal, 134, 225-238. 
Setubal, J.; dos Santos, P.; Goldman, B.; Ertesvåg, H.; Espin, G.; Rubio, L.; Valla, S.; Almeida, N.; Balasubramanian, D.; Cromes, L.; Curatti, L.; Du, Z.; Godsy, E.; Goodner, B.; Hellner-Burris, K.; Hernandez, J.; Houmiel, K.; Imperial, J.; Kennedy, C.; Larson, T.; Latreille, P.; Ligon, L.S.; Lu, J.; Mærk, M.; Miller, N.; Norton, S.; O'Carroll, I.; Paulsen, I.; Raulfs, E.; Roemer, R.; Rosser, J.; Segura, D.; Slater, S.; Stricklin, S.; Studholme, D.; Sun, J.; Viana, C.; Wallin, E.; Wang, B.; Wheeler, C.; Zhu, H.; Dean, D.; Dixon, R. \& Wood, D. (2009). The genome sequence of Azotobacter vinelandii, an obligate aerobe specialized to support diverse anaerobic metabolic processes. Journal of Bacteriology. 191(14), 4534-4545.

Skjak-Braek, G.; Grasdalen, H. \& Larsen, B. (1986). Monomer sequence and acetylation pattern in some bacterial alginates. Carbohydrates Research, 154, 239-250.

Smidsrod, O. \& Draget, K. (1996). Chemistry and physical properties of alginates. Carbohydrates European, 14, 6-12.

Socolofsky, M. \& Wyss, O. (1962). Resistance of the Azotobacter cyst. Journal of Bacteriology, $84,119-124$.

Steinbüchel, A. \& Luitke-Eversloh, T. (2003). Metabolic engineering and pathway construction for biotechnological production of relevant polyhydroxyalkanoates in microorganisms. Biochemical Engineering Journal, 16, 81-96.

Sun. H.; Pan,.; Zhigang, Y. \& Shi, M. (2007). The immune response and protective efficacy of vaccination with oral microparticle Aeromonas sobria vaccine in mice. International Immunopharmacology, 7, 1259-1264.

Sun, Z.; Ramsay J.; Guay M. \& Ramsay B. (2007). Fermentation process development for the production of medium chain length poly- $\beta$-hydroxyalkanoates. Applied Microbiology Biotechnology, 75, 475-485.

Suriyamongkol, P.; Weselake, R.; Narine, S.; Moloney, M. \& Shah, S. (2007). Biotechnological approaches for the production of polyhydroxyalkanoates in microorganisms and plants - A review. Biotechnology Advances. 25, 148-175.

Taguchi, S. \& Doi, Y. (2004) Evolution of polyhydroxyalkanoate (PHA) production system by "Enzyme Evolution": successful case studies of directed evolution. Macromolecules Bioscience, 4, 145-156.

Trujillo-Roldán, M.; Moreno, S.; Segura, D.; Galindo, E. \& Espín, G. (2003). Alginate production by an Azotobacter vinelandii mutant unable to produce alginate lyase. Applied Microbiology Biotechnology, 60, 733-737.

Trujillo-Roldán, M.; Moreno, S.; Espín, G. \& Galindo, E. (2004). The roles of oxygen and alginate-lyase in determining the molecular weight of alginate produced by Azotobacter vinelandii. Applied Microbiology Biotechnology, 63, 742-747.

Valappil, S.; Misra, K.; Boccaccini, A. \& Roy, I. (2006). Biomedical applications of polyhydroxyalkanoates, an overview of animal testing and in vivo responses. Expert Review of Medical Devices, 3 (6), 853-868.

Vázquez, A.; Moreno, S.; Guzmán, J.; Alvarado, A.; \& Espín, G. (1999). Transcriptional organization of the Azotobacter vinelandii algGXLVIFA genes: characterization of algF mutants. Gene, 232, 217-222.

Verlinden, R.; Hill, D.; Kenward, M.; Wiliams, C. \& Radecka, I. (2007). Bacterial synthesis of biodegradable polyhydroxyalkanoates, Journal of Applied Microbiology, 102, 14371449 . 
Wang, Z.; Wu, H.; Chen, J.; Zhang, J.; Yao, Y. \& Chen, G.-Q. (2008). A novel self-cleaving phasin tag for purification of recombinant proteins based on hydrophobic polyhydroxyalkanoate nanoparticles. Lab Chip, 8, 1957-1962.

Wang, H-H.; Zhou, X.; Liu, Q. \& Chen G-Q. (2011), Biosynthesis of polyhydroxyalkanoate homopolymers by Pseudomonas putida, Applied Microbiology and Biotechnology, 89, 1497-1507.

Williams, S. \& Martin, D. (2005). Applications of Polyhydroxyalkanoates (PHA) in Medicine and Pharmacy. Biopolymers Online. DOI: 10.1002/3527600035.bpol4004.

Wu, G.; Moir, A.; Sawers, G.; Hill, S. \& Poole R. (2001). Biosynthesis of polybetahydroxybutyrate (PHB) is controlled by CydR (Fnr) in the obligate aerobe Azotobacter vinelandii. FEMS Microbiology Letters, 194, 215-220.

Wu, Q.; Wang, Y. \& Chen G. (2009). Medical application of microbial biopolyesters Polyhydroxyalkanoates. Artificial Cells, Blood Substitutes, and Biotechnology, 37, 1-12.

Yang, J.-S.; Xie, Y.-J. \& He, W. (2011). Research progress on chemical modification of alginate: A review. Carbohydrate polymers, 84, 33-39.

Yao, Y., Zhan, X.; Zhang, J.; Zou, X.; Wang, Z.; Xiong, Y.; Chen, J. \& Chen, G. (2008). A specific drug targeting system based on polyhydroxyalkanoate granule binding protein PhaP fused with targeted cell ligands. Biomaterials, 29(36), 4823-4830.

Yasotha, K.; Aroua, M.; Ramachandran, K. \& Tan, I. (2006). Recovery of medium-chainlength polyhydroxyalkanoates (PHAs) through enzymatic digestion treatments and ultrafiltration, Biochemichal Engineering Journal, 30, 260-268.

Zapata-Vélez, A. \& Trujillo-Roldán, M. (2010). The lack of a nitrogen source and/or the C/N ratio affects the molecular weight of alginate and its productivity in submerged cultures of Azotobacter vinelandii. Annals of Microbiology, 60, 661-668.

Zhang, X.; Luo, R.; Wang, Z.; Deng, Y. \& Chen, G. (2009). Application of (R)-3hydroxyalkanoate methyl esters derived from microbial polyhydroxyalkanoates as novel biofuels. Biomacromolecules, 10, 707-711.

Zinn, M.; Witholt, B. \& Egli, T. (2001). Occurrence, synthesis and medical application of bacterial Polyhydroxyalkanoate. Advanced Drug Delivery Reviews, 53, 5-21.

Zinn, M.; Weilenmann, H.; Hany, R.; Schmid, M. \& Egli T. (2003). Tailored synthesis of poly R- $\beta$-hydroxybutyrate-co-hydroxyvalerate (PHB/HV) in Ralstonia euthropha DSM 428, Acta Biotechnologica, 23, 309-316. 


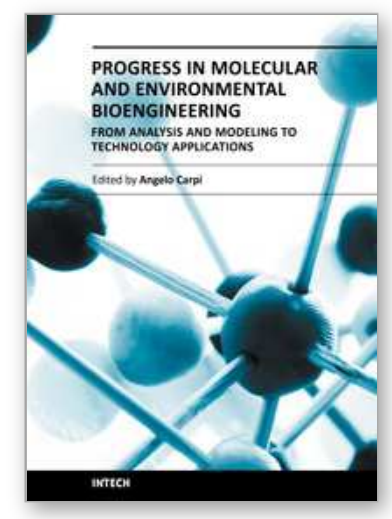

\author{
Progress in Molecular and Environmental Bioengineering - From \\ Analysis and Modeling to Technology Applications \\ Edited by Prof. Angelo Carpi
}

ISBN 978-953-307-268-5

Hard cover, 646 pages

Publisher InTech

Published online 01, August, 2011

Published in print edition August, 2011

This book provides an example of the successful and rapid expansion of bioengineering within the world of the science. It includes a core of studies on bioengineering technology applications so important that their progress is expected to improve both human health and ecosystem. These studies provide an important update on technology and achievements in molecular and cellular engineering as well as in the relatively new field of environmental bioengineering. The book will hopefully attract the interest of not only the bioengineers, researchers or professionals, but also of everyone who appreciates life and environmental sciences.

\title{
How to reference
}

In order to correctly reference this scholarly work, feel free to copy and paste the following:

Carlos Peña, Tania Castillo, Cinthia Núñez and Daniel Segura (2011). Bioprocess Design: Fermentation Strategies for Improving the Production of Alginate and Poly- $\beta$-Hydroxyalkanoates (PHAs) by Azotobacter vinelandii, Progress in Molecular and Environmental Bioengineering - From Analysis and Modeling to Technology Applications, Prof. Angelo Carpi (Ed.), ISBN: 978-953-307-268-5, InTech, Available from: http://www.intechopen.com/books/progress-in-molecular-and-environmental-bioengineering-from-analysisand-modeling-to-technology-applications/bioprocess-design-fermentation-strategies-for-improving-theproduction-of-alginate-and-poly-hydroxya

\section{INTECH}

open science | open minds

\author{
InTech Europe \\ University Campus STeP Ri \\ Slavka Krautzeka 83/A \\ 51000 Rijeka, Croatia \\ Phone: +385 (51) 770447 \\ Fax: +385 (51) 686166 \\ www.intechopen.com
}

\author{
InTech China \\ Unit 405, Office Block, Hotel Equatorial Shanghai \\ No.65, Yan An Road (West), Shanghai, 200040, China \\ 中国上海市延安西路65号上海国际贵都大饭店办公楼 405 单元 \\ Phone: +86-21-62489820 \\ Fax: +86-21-62489821
}


(C) 2011 The Author(s). Licensee IntechOpen. This chapter is distributed under the terms of the Creative Commons Attribution-NonCommercialShareAlike-3.0 License, which permits use, distribution and reproduction for non-commercial purposes, provided the original is properly cited and derivative works building on this content are distributed under the same license. 